\title{
Does Rotavator Use in Taiwanese Rice Paddies Expose Reptiles to Increased Opportunistic Avian Predation?
}

\author{
Jean-Jay Mao ${ }^{1}$ and Gerrut Norval ${ }^{2}$
}

${ }^{1}$ Department of Forestry and Natural Resources, National Ilan University, No. 1, Shen-Lung Rd., Sec. 1, Yilan City 260, Taiwan, R.O.C. (jjmao@niu.edu.tw) ${ }^{2}$ Applied Behavioural Ecology \& Ecosystem Research Unit, Department of Nature Conservation, UNISA, Private Bag X6, Florida, 1710, Republic of South Africa

$\mathrm{H}$ abitat destruction and modification is one of the most serious anthropogenic threats to biodiversity (Tilman et al. 1997, Krauss et al. 2010). Nevertheless, not all species are negatively affected by such alterations. Some species are able to adapt as human commensals, and may even thrive in human-created habitats (Blair 1996, Bambaradeniya et al. 1998). Rice paddies are among the most common humancreated habitats in Asia (Bambaradeniya and Amerasinghe 2003), where rice has been cultivated for thousands of years (Takaya 1977, Fairhurst and Dobermann 2002); consequently, a variety of aquatic and semi-aquatic animals have adapted to exploiting this habitat type. In Taiwan, vertebrate wildlife most commonly associated with lowland rice paddies includes egrets (Severinghaus et al. 2010), such as Cattle Egrets (Bubulcus ibis [Linnaeus, 1758]) and Little Egrets (Egretta garzetta [Linnaeus, 1766]), snakes and frogs (Shang et al. 2009; Fig. 1), and fishes (Lin 2007). When fields are tilled, flocks of egrets gather and follow the tractor-driven rotavator (a machine pulled by a tractor with rotating blades that till the top layers of the soil) to feed on prey disturbed or exposed by the machine.

On 18 April 2008, the senior author observed a flock of egrets actively feeding in a tilled rice paddy (Fig. 2). A closer inspection revealed that one E. garzetta was attempting to capture a medium-sized snake. A B. ibis, attracted by the feeding E. garzetta, tried to steal the prey. When the snake struck in defense, both birds retreated a short distance. We identified the snake as a female Checkered Keelback (Xenochrophis piscator [Schneider 1799]) (Fig. 3). The snake had a snoutvent length of $458 \mathrm{~mm}$, tail length of $89 \mathrm{~mm}$ (the tail tip was missing), and a body mass of $33.7 \mathrm{~g}$. A detailed examination of the snake revealed that it had a ventral scale count of 140 , and that the vertebrae in the region of ventral scales $85-90$ appeared to have been broken by the rotavator (Fig. 3). Some of the snake's internal organs also were damaged, so it was euthanized with an overdose of ether and deposited in the herpetological collection of the Department of Forestry and Natural Resources, National Ilan University (NIU-FNR0210043).

The driver of the tractor stated that he had observed $X$. piscator, an Oriental Ratsnake (Ptyas mucosa [Linnaeus 1758]), and a soft-shelled turtle (Pelodiscus sinensis [Wiegmann 1835]) that had been sliced into pieces by the machine and were scavenged by egrets. In Taiwan, B. ibis and E. garzetta in rice paddies are known to prey on arthropods, earthworms, mollusks, frogs and their tadpoles (Severinghaus et al. 2010), and the Indian Forest Skink (Sphenomorphus indicus [Gray 1853]) (Mao, pers. obs.). Studies from other parts of the birds' distribution confirm that their prey consists primarily of small arthropods and other invertebrates, small frogs, fish, and lizards (Hanebrink and Denton 1969, Tojo 1996, Petrescu 1999), but also includes small snakes (Fogarty and Hetrick 1973, Ashoori 2010) and small mammals (rodents; Si Bachis et al. 2001). In addition, Si Bachis et al. (2001) stated that

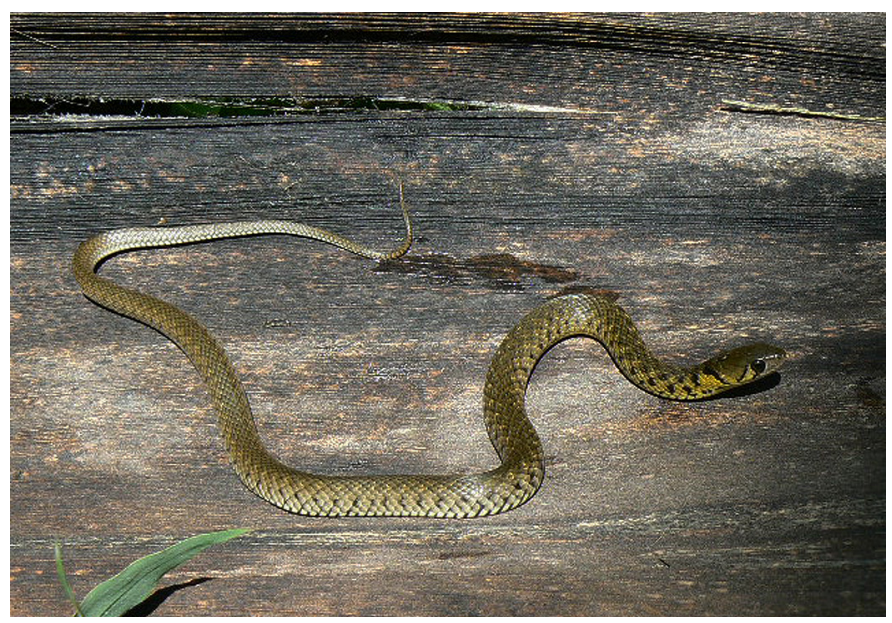

Fig. 1. A juvenile Checkered Keelback (Xenochrophis piscator), a species commonly associated with lowland rice paddies in Taiwan (photograph by Gerrut Norval). 


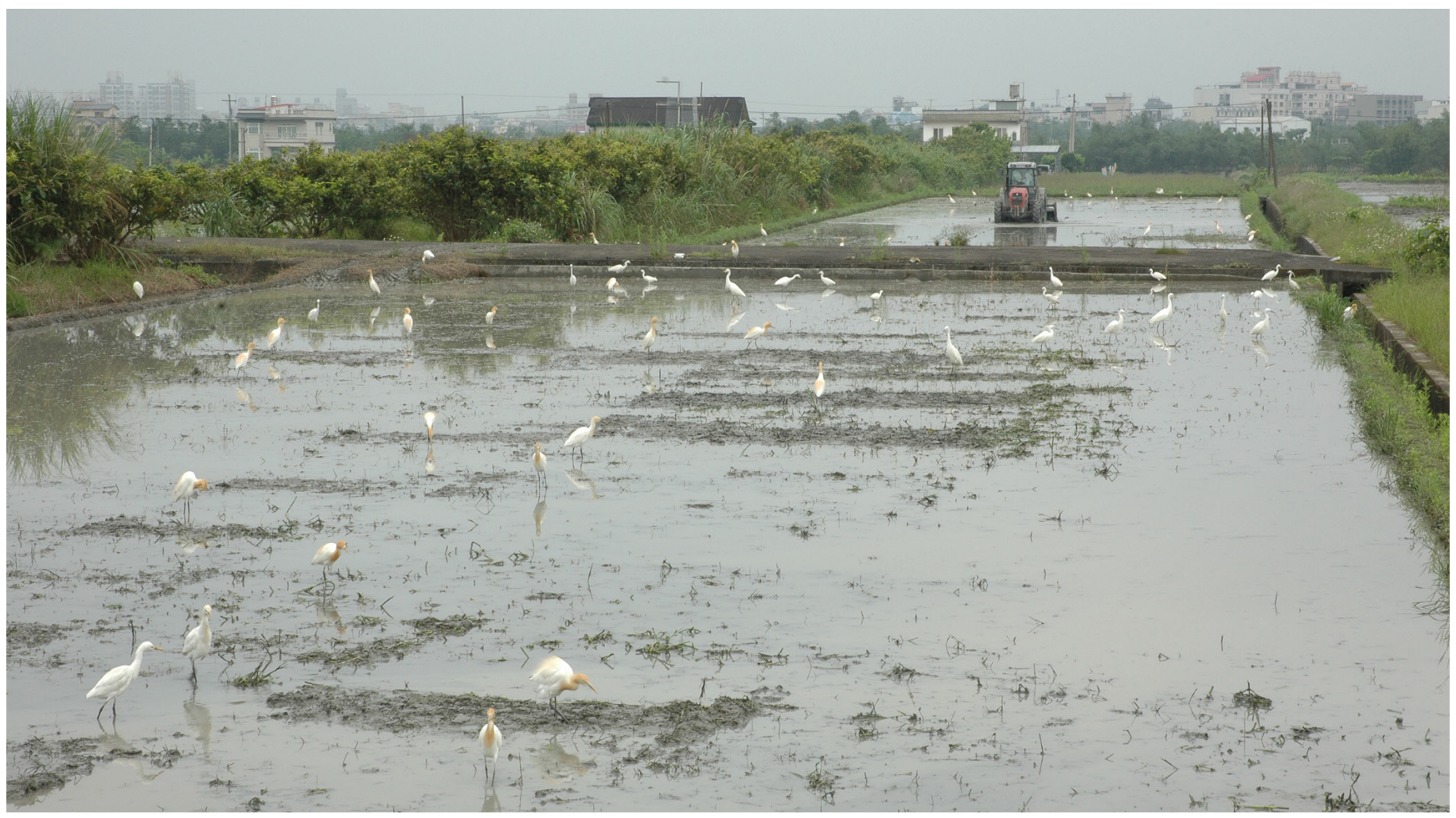

Fig. 2. Egrets aggregate and follow a tractor-driven rotavator in a Taiwanese rice paddy (photograph by Jean-Jay Mao).
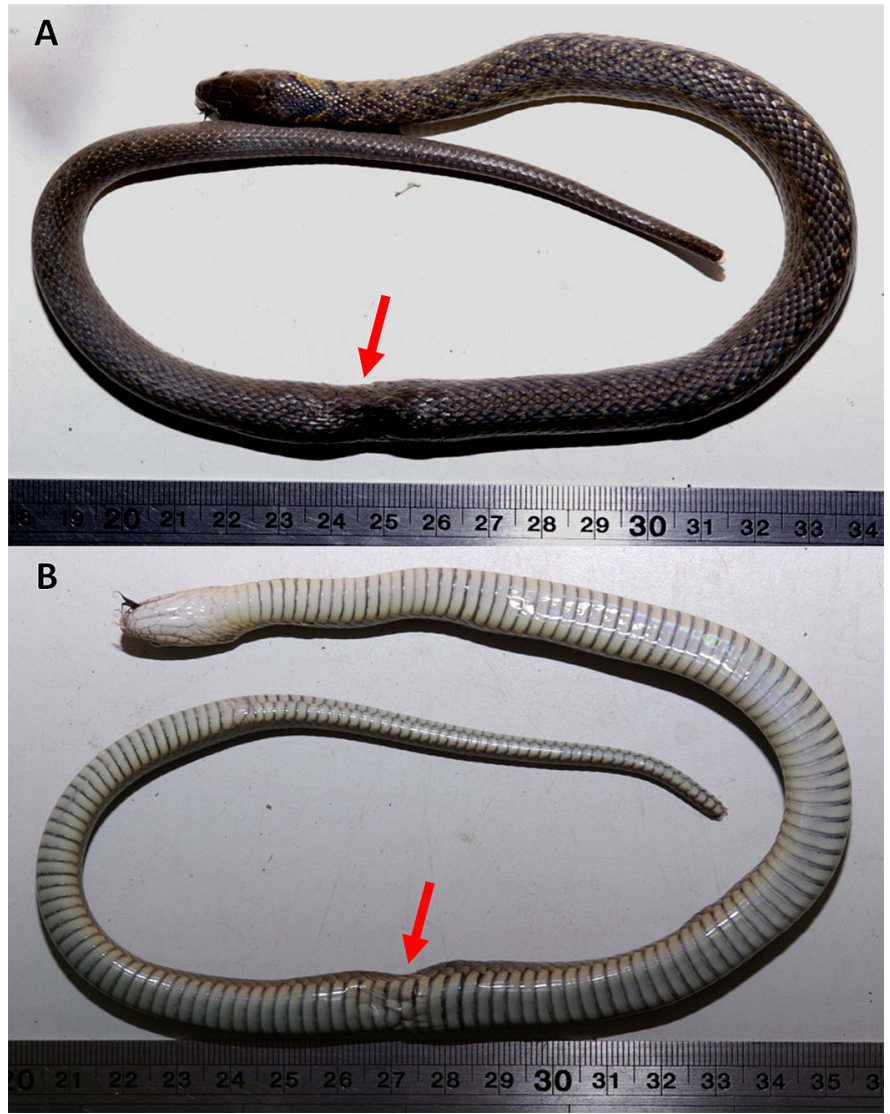

Fig. 3. A dorsal (A) and ventral (B) view of a female Checkered Keelback (Xenochrophis pisator) injured by a tractor-driven rotavator in a Taiwanese rice paddy. Red arrows indicate the position where vertebrae were broken by the rotavator (photograph by Jean-Jay Mao).
B. ibis exhibits a high degree of ecological versatility, Dinsmore (1973) reported a higher foraging success rate for these birds in the presence of cattle and/or agricultural machinery, and Kazantzidis and Goutner (1996) demonstrated that rice paddies play an important role in the feeding habits of $E$. garzetta.

Our observations reconfirm the plasticity in prey selection exhibited by B. ibis and E. garzetta feeding in humancreated habitats. They also illustrate that prey, which would usually be too large for these birds to capture, can be utilized if it is immobilized by intentional or accidental human actions. Although an increase of food would be beneficial for the conservation of the birds, the use of tractor-driven rotavators in rice paddies most certainly has a negative impact on populations of the amphibians and reptiles that exploit these habitats. Because the human population is increasing and the cultivation of rice and other grains can be expected to increase proportionately, the redesign of rotavators to avoid killing some macro-fauna, such as aquatic snakes and chelonians, should be considered.

\section{Literature Cited}

Ashoori, A. 2010. Breeding biology and success of the Little Egret Egretta garzetta in Karfestan Ab-bandan, Roudsar, Gilan Province, northern Iran. Podoces 5:29-34.

Bambaradeniya, C.N.B. and F.P. Amerasinghe. 2003. Biodiversity associated with the rice field agroecosystem in Asian countries: A brief review. Working Paper 63. International Water Management Institute, Colombo, Sri Lanka.

Bambaradeniya, C.N.B., K.T. Fonseka, and C.L. Ambagahawatte. 1998. A preliminary study of fauna and flora of a rice field in Kandy, Sri Lanka. Ceylon Journal of Science (Biological Science) 25:1-22. 
Blair, R.B. 1996. Land use and avian species diversity along an urban gradient. Ecological Applications 6:506-519.

Dinsmore, J.J. 1973. Foraging success of Cattle Egrets, Bubulcus ibis. American Midland Naturalist 89:242-246.

Fairhurst, T.H. and A. Dobermann. 2002. Rice in the global food supply. Better Crops International 16 (Special Supplement):3-6.

Fogarty, M.J. and W.M. Hetrick. 1973. Summer foods of Cattle Egrets in north central Florida. The Auk 90:268-280.

Hanebrink, E.L. and G. Denton. 1969. Feeding behavior and analysis of regurgitated food collected from the Cattle Egret (Bubulcus ibis) and the Little Blue Heron (Florida caerulea). Arkansas Academy of Science Proceedings 23:74-79.

Kazantzidis, S. and V. Goutner. 1996. Foraging ecology and conservation of feeding habitats of Little Egrets (Egretta garzetta) in the Axios River Delta, Macedonia, Greece. Colonial Waterbirds 19:115-121.

Krauss, J., R. Bommarco, M. Guardiola, R. Heikkinen, A. Helm, M. Kuussaari, R. Lindborg, E. Öckinger, M. Pärtel, J. Pino, J. Pöyry, K. Raatikainen, A. Sang, C. Stefanescu, T. Teder, M. Zobel, and I. Steffan-Dewenter. 2010. Habitat fragmentation causes immediate and time-delayed biodiversity loss at different trophic levels. Ecology Letters 13:597-605.

Lin, C.J. 2007. A Field Guide to the Freshwater Fish and Shrimp of Taiwan. Vol. 1.
Big Trees Publishers, Taipei, Taiwan (in Chinese).

Petrescu, A. 1999. Food of some herons, Glossy Ibis, and spoonbill (Aves: Ardeidae and Threskiornithidae) in south-eastern Romania. Travaux du Museum National d'Histoire Naturelle 'Grigore Antipa'41:393-414.

Severinghaus, L.L., T.S. Ding, W.H. Fang, W.H. Lin, M.C. Tsai, and C.W. Yen. 2010. The Avifauna of Taiwan. Vol. 1. Forestry Bureau, Council of Agriculture, Taiwan, R.O.C. (in Chinese).

Shang, G.S., P.S. Lee, and Y.J. Yang. 2009. A Field Guide to the Amphibians and Reptiles of Taiwan. Owl Publishing House Co., Ltd. Taipei, Taiwan (in Chinese).

Si Bachis, A., H. Hafner, J.N. Tourenq, S. Doumandji, and S. Lek. 2001. Diet of adult Cattle Egrets (Bubulcus ibis) in a new north African colony (Soummam, Kabylie, Algeria): Taxonomic composition and seasonal variability. Ardeola 48:217-223.

Takaya, Y. 1977. Rice growing societies of Asia: An ecological approach. South East Asian Studies 15:442-451.

Tilman, D., C.L. Lehman, and C. Yin. 1997. Habitat destruction, dispersal, and deterministic extinction in competitive communities. American Naturalist 149:407-435.

Tojo, H. 1996. Habitat selection, foraging behaviour and prey of five heron species in Japan. Japanese Journal of Ornithology 45:141-158. 